\title{
Change in hardness of an as-cast and softening heat-treated low-gold-content alloy for bonding porcelain by simulated porcelain firing and its mechanism
}

\author{
Sung-Min Kim ${ }^{1}$ - Hyung-Il Kim ${ }^{1} \cdot$ Yong Hoon Kwon ${ }^{1}$ Hyo-Joung Seol ${ }^{1}$
}

Published online: 2 July 2015

(C) The Author(s) 2015. This article is published with open access at SpringerLink.com

\begin{abstract}
This study examined the change in hardness of a low-gold-content alloy for bonding porcelain induced by simulated porcelain firing after casting and softening heat treatment along with its mechanism. In the as-cast specimen, the hardness was increased by oxidation, and as the specimen underwent a further porcelain-firing process, the hardness decreased gradually to be softer than the as-cast state. The hardening in the as-cast specimen by oxidation was induced by the grain interior precipitation of the ordered $\mathrm{Pd}_{3}(\mathrm{Sn}, \mathrm{In})$ phase, which resulted in the formation of severe lattice strain in the matrix. Softening by the complete firing process in the as-cast specimen was due to the coarsening of the ordered $\mathrm{Pd}_{3}(\mathrm{Sn}, \mathrm{In})$ precipitates, which resulted in release of lattice strain by the reduced interphase boundaries between the coarsened precipitates and surrounding matrix. In the softening heat-treated specimen before simulated porcelain firing, the decrease in hardness by the softening heat treatment, which was performed to allow easy alloy processing before porcelain firing, was almost recovered in the oxidation-treated state, which is the first stage of the porcelain-firing cycles. From the first opaque-treated state, there was little difference between the hardness of the as-cast specimen and softening heat-treated specimens. The mechanism of hardening by oxidation and subsequent softening by the complete firing process was unaffected by the softening heat treatment before porcelain firing in a low-gold-content alloy for bonding porcelain.
\end{abstract}

Hyo-Joung Seol

seolhyojoung@daum.net

1 Department of Dental Materials, Institute of Translational Dental Sciences, School of Dentistry,, Pusan National University, Beomeo-Ri, Mulgeum-Eup,

Yangsan-Si, Gyeongsangnam-Do 626-814, South Korea
Keywords Low-gold-content alloy for bonding porcelain . Simulated porcelain firing $\cdot$ Hardening and softening mechanism $\cdot$ Cooling rate $\cdot$ Grain interior precipitation

\section{Introduction}

Porcelain firing for the fabrication of metal-ceramic prostheses is performed several times on dental alloys for bonding porcelain over the temperature range $890-980{ }^{\circ} \mathrm{C}$. During porcelain firing, dental precious alloys for bonding porcelain are normally softened. Then during cooling to room temperature, the alloys can be hardened to some extent by atomic ordering or precipitation of the alloy components $[1,2]$. Therefore, depending on the composition, the alloy becomes much softer after several porcelain-firing cycles [3-5].

Dental alloys for bonding porcelain undergo processing, such as trimming for adaptation on a master model before porcelain firing. In the case of alloys with a high gold content, they have a soft surface by poor hardness after casting, which leads to poor properties for processing, such as overlapping on the surface after grinding, resulting in the formation of porosity at the metal-ceramic interface [6]. Therefore, several studies have been performed to improve the hardness of the casted high-gold-content alloy for bonding porcelain by proper heat treatment prior to processing and porcelain firing $[7,8]$. Compared to the high-gold-content alloy, the low-gold-content alloy for bonding porcelain is much harder after casting, which also makes processing difficult or time consuming. To resolve this, a softening heat treatment can be attempted prior to processing the casted low-gold-content alloy for bonding porcelain. On the other hand, in the softening heat-treated specimen for easy alloy processing, possible further softening by subsequent porcelain firing can occur, which will cause problems, such as sag and thermal distortion of the alloy during porcelain 
Table 1 Chemical composition of the specimen alloy

\begin{tabular}{lllrlll}
\hline Composition & $\mathrm{Pd}$ & $\mathrm{Ag}$ & $\mathrm{Au}$ & $\mathrm{Sn}$ & $\mathrm{In}$ & $\mathrm{Ru}$ \\
\hline Wt. \% & 49.6 & 27.8 & 13.5 & 4.6 & 4.4 & 0.1 \\
At. \% & 53.6 & 29.6 & 7.9 & 4.5 & 4.4 & 0.11 \\
\hline
\end{tabular}

firing. Therefore, the change in hardness of low-gold-content alloy during porcelain-firing process need to be analyzed in both the as-cast and softening heat-treated states in order to attempt the softening heat treatment before porcelain-firing process. This study examined the change in hardness and its mechanism of the as-cast and softening heat-treated low-goldcontent alloy for bonding porcelain during simulated porcelain firing by analyzing the change in hardness, microstructure, phase transformation, and elemental distribution.

\section{Materials and methods}

\section{Specimen alloy}

The specimen alloy used in this study was a low-gold-content alloy for bonding porcelain (Aurolite 2A, Aurium Research, USA) with a white color and fine grain. The manufacturer reported the alloy to have a melting range of $1,270 \sim 1$, $335^{\circ} \mathrm{C}$ and a casting temperature of $1,425^{\circ} \mathrm{C}$. Table 1 lists the chemical composition of the specimen alloy supplied by the manufacturer. The phosphate-bonded precision investment (Univest plus, Metalor Dental, Switzerland), which is fine grained and graphite-free, was used to prepare the specimen casting. The alloy specimens were melted using a multiorifice gas-oxygen torch, cast centrifugally in a broken-arm casing machine (Centrifugal Casting Machine, Osung, South Korea), and then bench cooled to room temperature. After divesting, the specimens were cleaned using an ultrasonic cleaner (Bransonic, Branson, USA) for $30 \mathrm{~min}$. The specimens obtained were in the form of small square pieces, $10 \times 10 \times 0.8 \mathrm{~mm}$ in size.

\section{Heat treatment}

Two types of softening heat treatments for easy alloy processing were performed before simulated porcelain firing. For this, the abovementioned as-cast platelike specimen was heat treated at $1,100{ }^{\circ} \mathrm{C}$ for $10 \mathrm{~min}$ in a dental porcelain furnace (Multimat 2 torch, Dentsply, Germany) and then cooled at two different cooling rates, i.e., cooled by rapid quenching into ice brine or cooled in a firing chamber, which was opened by approximately $50 \mathrm{~mm}$. The as-cast specimen and softening heat-treated specimens were then porcelain firing simulated in a dental porcelain furnace according to the porcelain-firing cycles listed in Table 2.

\section{Hardness test}

The hardness of the heat-treated specimens was measured to determine the changes in hardness during the porcelain-firing process using a Vickers microhardness tester (MVK-H1, Akashi Co., Japan) with $300 \mathrm{gf}$ load and dwell time of $10 \mathrm{~s}$. The hardness values recorded are the mean of five measurements.

\section{Field emission scanning electron microscopy (FE-SEM)}

The microstructural changes of the heat-treated specimens during the porcelain-firing process were examined by FESEM (JSM-6700 F, Jeol, Japan). The specimens were polished metallographically and etched in an aqueous solution containing $10 \% \mathrm{KCN}$ (potassium cyanide) and $10 \%$ $\left(\mathrm{NH}_{4}\right)_{2} \mathrm{~S}_{2} \mathrm{O}_{8}$ (ammonium persulfate). The surfaces of the specimens were observed by FE-SEM at $15 \mathrm{kV}$.

\section{X-ray diffraction (XRD)}

XRD (XPERT-PRO, Philips, Netherlands) was performed to examine the phase transformation of the heat-treated specimens during the porcelain-firing process. The XRD profile was recorded at $30 \mathrm{kV}$ and $40 \mathrm{~mA}$ using Ni-filtered $\mathrm{Cu} \mathrm{k \alpha}$

Table 2 Simulated porcelain-firing cycles

\begin{tabular}{|c|c|c|c|c|c|c|c|}
\hline Firing cycles & Predrying (min) & Heat rate $\left({ }^{\circ} \mathrm{C} / \mathrm{min}\right)$ & Start temp. $\left({ }^{\circ} \mathrm{C}\right)$ & Final temp. $\left({ }^{\circ} \mathrm{C}\right)$ & Hold time (min) & Vacuum time (min) & Vaccum level \\
\hline Oxidation & 0 & 60 & 650 & 1040 & 10 & 0 & 0 \\
\hline First opaque & 5 & 60 & 650 & 980 & 1 & $05: 30$ & 70 \\
\hline Second opaque & 5 & 60 & 650 & 970 & 1 & $05: 20$ & 70 \\
\hline Main bake & 5 & 60 & 650 & 930 & 1 & $04: 40$ & 70 \\
\hline Correction & 5 & 60 & 650 & 920 & 1 & 04:30 & 70 \\
\hline Glaze & 5 & 60 & 650 & 900 & 0 & 0 & 0 \\
\hline
\end{tabular}


Table 3 Cooling rate during simulated porcelain-firing cycles

\begin{tabular}{llllll}
\hline Cooling rate & Quick cooling & Stage 0 & Stage 1 & Stage 2 & Stage 3 \\
\hline Condition & $\begin{array}{c}\text { Firing chamber moves } \\
\text { immediately to upper end } \\
\text { position and air-cooled }\end{array}$ & $\begin{array}{c}\text { Firing chamber moves } \\
\text { immediately to upper } \\
\text { end position }\end{array}$ & $\begin{array}{c}\text { Firing chamber } \\
\text { opens about } 70 \mathrm{~mm}\end{array}$ & $\begin{array}{c}\text { Firing chamber } \\
\text { opens about 50 mm }\end{array}$ & $\begin{array}{c}\text { Firing chamber } \\
\text { remains closed }\end{array}$ \\
\hline
\end{tabular}

radiation as the incident beam. The scanning rate of a goniometer was $1^{\circ}(2 \theta / \mathrm{min})$.

\section{Energy-dispersive spectrometer (EDS) analysis}

The elemental distribution of the heat-treated specimens was examined using an energy dispersive X-ray spectrometer (INCA x-sight, Oxford Instruments Ltd., UK) attached to the FESEM at $15 \mathrm{kV}$.

\section{Results and discussion}

\section{Effects of the cooling rates on change in hardness by simulated porcelain firing}

During porcelain firing, precious alloys for bonding porcelain are normally softened, and such softening can be minimized depending on the rate of cooling after porcelain firing. To determine the effective cooling rate to minimize alloy softening by porcelain firing, the change in hardness at various cooling rates after porcelain firing was determined. For this, the casted alloy was solution treated by quenching into ice brine after heating for $10 \mathrm{~min}$ in a porcelain furnace of 1 , $100{ }^{\circ} \mathrm{C}$. The alloy was then oxidation treated, which is the first stage of the firing cycles in Table 2 . The specimens were cooled to $600{ }^{\circ} \mathrm{C}$ after the oxidation treatment at five cooling rates, as listed in Table 3 . The alloys were then bench cooled to room temperature. Table 4 lists the change in hardness at various cooling rates. By the fast or slow cooling rates, the minimum hardness was obtained, and at an intermediate cooling rate, stage 2 , the maximum hardness (223.74 HV) was obtained. Such a tendency was also reported in the $\mathrm{CuPt}$ alloy, where the most effective order-hardening occurred during cooling at an intermediate cooling rate [9]. From the above, during cooling at the cooling rate in stage 2 , the alloy appeared to undergo atomic ordering or precipitation of the components, as will be discussed further.

\section{Change in hardness of the as-cast and softening heat-treated alloys by simulated porcelain firing}

The change in hardness of the as-cast and softening heattreated specimens during the complete porcelain-firing process was investigated. For this, two types of softening heat treatments (solution treatment and prefiring heat treatment) for easy alloy processing were performed before simulated porcelain firing on the casted alloys. First, the casted alloys were heated in a porcelain furnace of $1,100{ }^{\circ} \mathrm{C}$ for $10 \mathrm{~min}$, and cooled at two different cooling rates, i.e., quenching and stage 2. By quenching, the alloy became the softest (solution treatment), and by cooling at stage 2 , the alloy became effectively hard compared to the soft state (prefiring heat treatment). After the solution treatment, the as-cast specimen $(233.14 \mathrm{HV})$ was softened to $138.18 \mathrm{HV}$, and after prefiring heat treatment, the as-cast specimen was softened to $213.88 \mathrm{HV}$. This suggests that proper softening for easy alloy processing can be achieved by cooling the alloy without strict control of the cooling rate after heating in a porcelain furnace of $1,100{ }^{\circ} \mathrm{C}$.

To observe the change in hardness during the complete porcelain-firing process, the as-cast specimen and solutiontreated (S.T.) or prefiring heat-treated specimens after casting were porcelain firing simulated according to the complete firing schedule listed in Table 2. The cooling rate after firing was controlled to stage 2 for each specimen. Figure 1 presents the change in hardness for each specimen during simulated porcelain firing. The hardness of the as-cast specimen increased to the maximum value, $245.48 \mathrm{HV}$, by oxidation. On the other hand, the hardness decreased gradually as the specimen underwent further firing process and, finally, became 213.8 HV after complete firing. In the solution-treated (S.T.) specimen after casting, the hardness apparently increased to 223.25 HV by oxidation and then increased further by the first opaque. As observed in the as-cast specimen, the hardness began to decrease with further firing process and, finally, became 203.2 HV after complete firing. In the prefiring heattreated specimen after casting, the hardness increased to the maximum value, $238.04 \mathrm{HV}$ by oxidation. By further firing process until glaze, the hardness decreased gradually to
Table 4 Hardness change by various cooling rate during oxidation treatment

\begin{tabular}{llllll}
\hline Cooling rate & Quick cooling & Stage 0 & Stage 1 & Stage 2 & Stage 3 \\
\hline Hardness (HV) & $139.26( \pm 4.62)$ & $155.32( \pm 5.74)$ & $151.56( \pm 3.84)$ & $223.74( \pm 9.64)$ & $127.95( \pm 10.09)$ \\
\hline
\end{tabular}




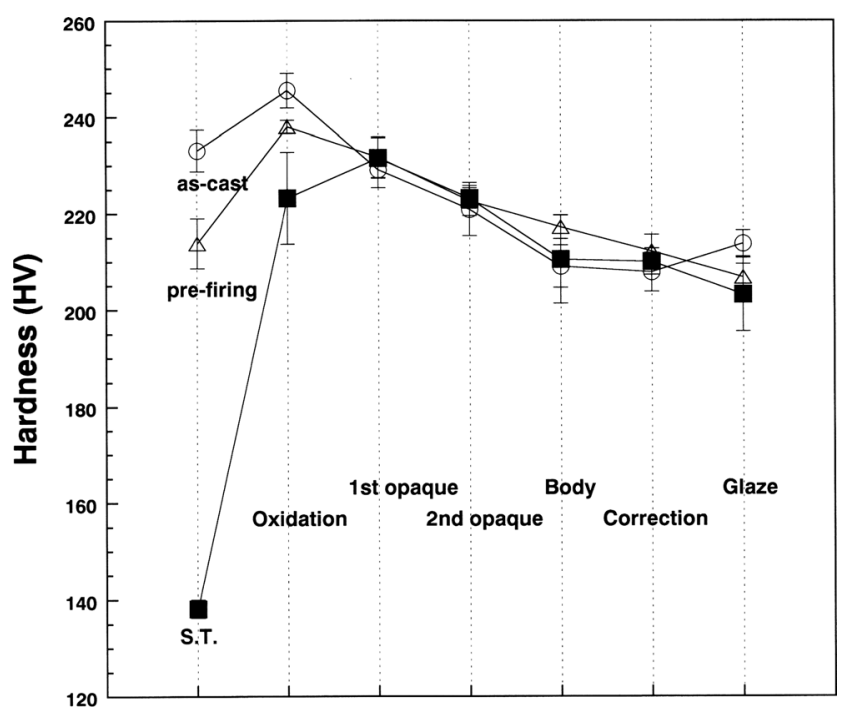

Fig. 1 Change in hardness in the as-cast specimen, solution-treated (S.T.), or prefiring heat-treated specimens after casting during simulated porcelain firing

206.78 HV. Therefore, from the first opaque, there was little difference among the hardness of the as-cast specimen, solution-treated and prefiring heat-treated specimens after casting. From the above, it was found that the softening effect of solution treatment or prefiring heat treatment almost disappeared at oxidation, the first stage of the firing cycles. Therefore, the risk of sag and thermal distortion will not increase during porcelain firing by such a softening heat treatment for easy alloy processing.

\section{Microstructural changes in the as-cast and softening heat-treated alloys by simulated porcelain firing}

The microstructural changes by simulated porcelain firing in the as-cast specimen and softening heat-treated specimens were observed by FE-SEM. Figures 2 to 4 present FE-SEM images of $\times 5,000$ (1) and $\times 20,000$ (2) of the as-cast specimen (Fig. 2a), solution-treated (Fig. 3a) or prefiring heat-treated (Fig. 4a) specimens after casting. In Figs. 2 to 4, (b) and (c) correspond to their oxidation-treated state and complete firing-simulated state, respectively. In Fig. 2a, the as-cast specimen exhibited an equiaxed structure containing grain boundary precipitates with a lamellar structure. The cubiclike precipitates were also observed adjacent to the grain boundary, and the grain interior region appeared to be relatively
Fig. 2 Microstructural change in the as-cast specimen during simulated porcelain firing: as-cast (a), oxidation treated after casting (b), and complete firing simulated (c) at magnifications of $\times 5,000(1)$ and $\times 20,000(2)$
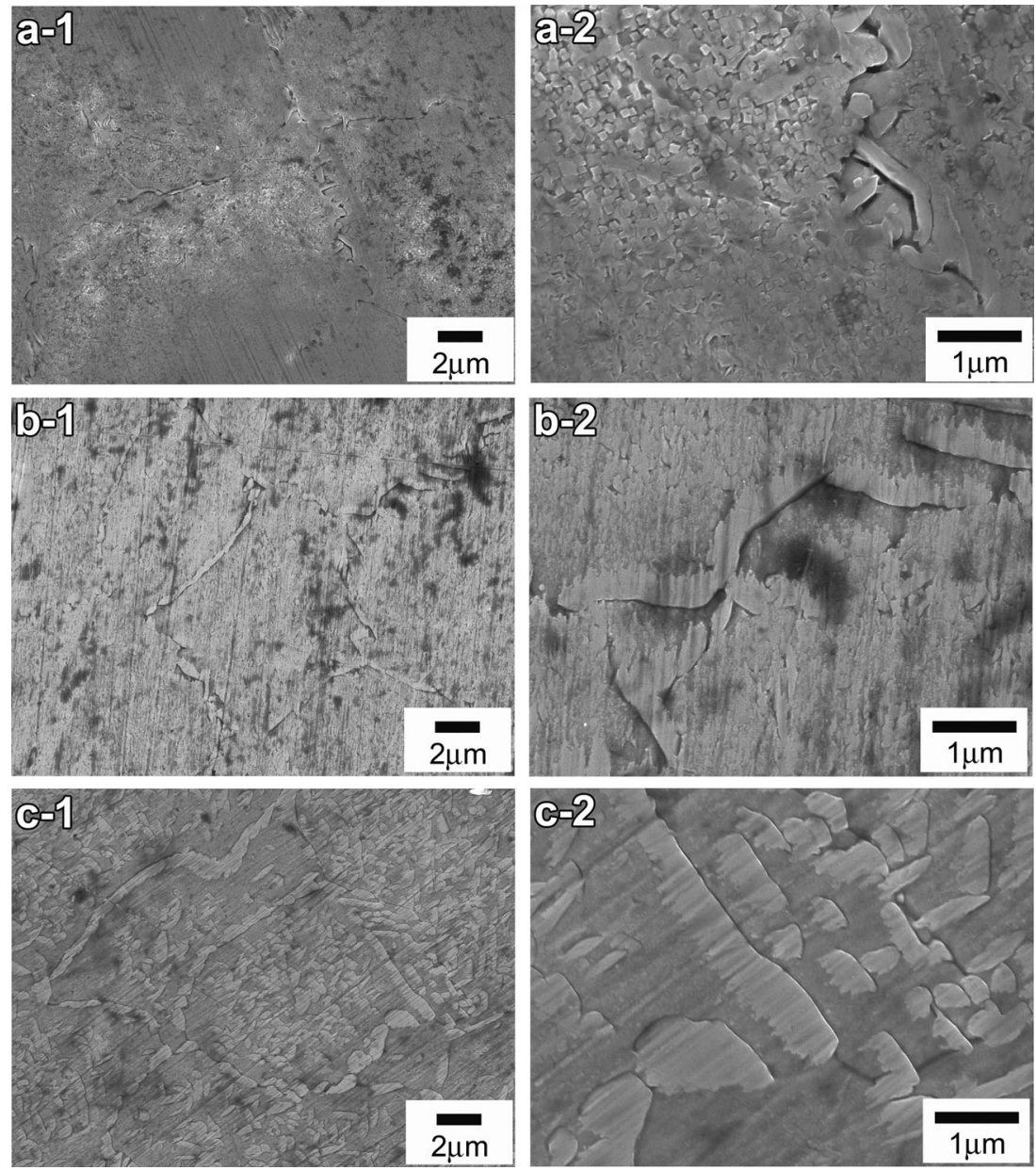
Fig. 3 Microstructural change in the solution-treated (S.T.) specimen during simulated porcelain firing: solution treated (S.T.) after casting (a), oxidation treated after S.T. (b), and complete firing simulated $(\mathbf{c})$ at magnifications of $\times 5,000(1)$ and $\times 20,000(2)$
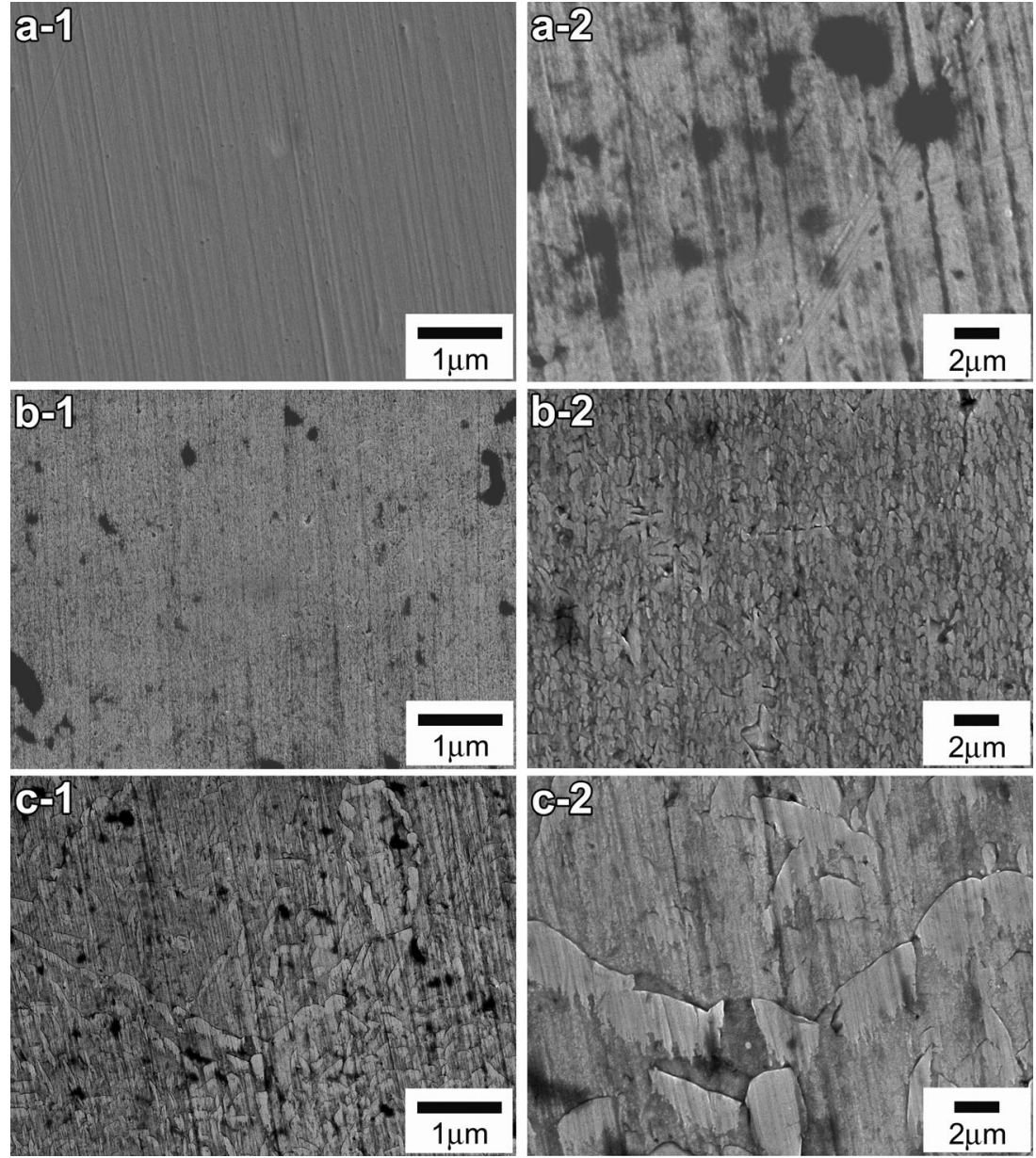

homogenized. In the oxidation-treated specimen after casting (Fig. 2b), the lamellar precipitates of the grain boundary were observed, but cubiclike precipitates adjacent to the grain boundary disappeared, and particlelike precipitates formed in the entire grain interior region. From the microstructural change, it is believed that during oxidation at $1,040{ }^{\circ} \mathrm{C}$ for $10 \mathrm{~min}$, precipitates in the grain interior and grain boundary melt into the matrix, and then during the cooling process, the solutes reprecipitate in the grain interior and boundaries. The continuous precipitation in the entire grain interior appears to be the main reason for the increase in hardness, as will be discussed further. By simulated complete firing (Fig. 2c), the grain boundary precipitates showed little change, but the grain interior precipitates apparently coarsened. Newly formed finegrained interior precipitates were also observed in the matrix. Considering the decrease in hardness despite the formation of fine precipitates in the matrix, the microstructural coarsening of the grain interior precipitates is believed to have strongly contributed to the decrease in hardness, as will be discussed further. Such softening from microstructural coarsening has been reported in many dental casting alloys that are overaged for long periods of time at temperatures where age-hardening occurs [10-12]. Compared to dental casting alloys, dental alloys for bonding porcelain undergo heat treatment at much higher temperatures for porcelain firing, which resulted in apparent microstructural coarsening during a much shorter firing time [13].

In the solution-treated specimen after casting in Fig. 3a, the precipitates observed in the as-cast specimen disappeared, and a single phase was obtained. In the oxidation-treated specimen after the solution treatment (Fig. 3b), particle-like grain interior precipitates covered the entire matrix region, as observed in the oxidation-treated specimen after casting (Fig. 2b). These grain interior precipitates resulted in a $73 \mathrm{HV}$ increase in hardness from the solution-treated state. By simulated complete firing after the solution treatment (Fig. 3c), besides the appearance of grain boundary precipitates, the grain interior precipitates were apparently coarsened, and fine precipitates were observed in the matrix, as observed in the complete firing-simulated specimen after casting (Fig. 2c).

In the prefiring heat-treated specimen after casting in Fig. 4a-1, the microstructure was similar to a single phase, but at a $\times 20,000$ magnification (Fig. 4a-2), fine precipitates were confirmed to cover the entire matrix region. Concomitant to such a microstructural difference with the solutiontreated specimen of Fig. 3a, the hardness of the prefiring 
Fig. 4 Microstructural change in the prefiring heat-treated specimen during simulated porcelain firing: prefiring treated after casting (a), oxidation treated after prefiring heat treatment (b), and complete firing simulated (c) at magnifications of $\times 5,000(1)$ and $\times 20,000(2)$
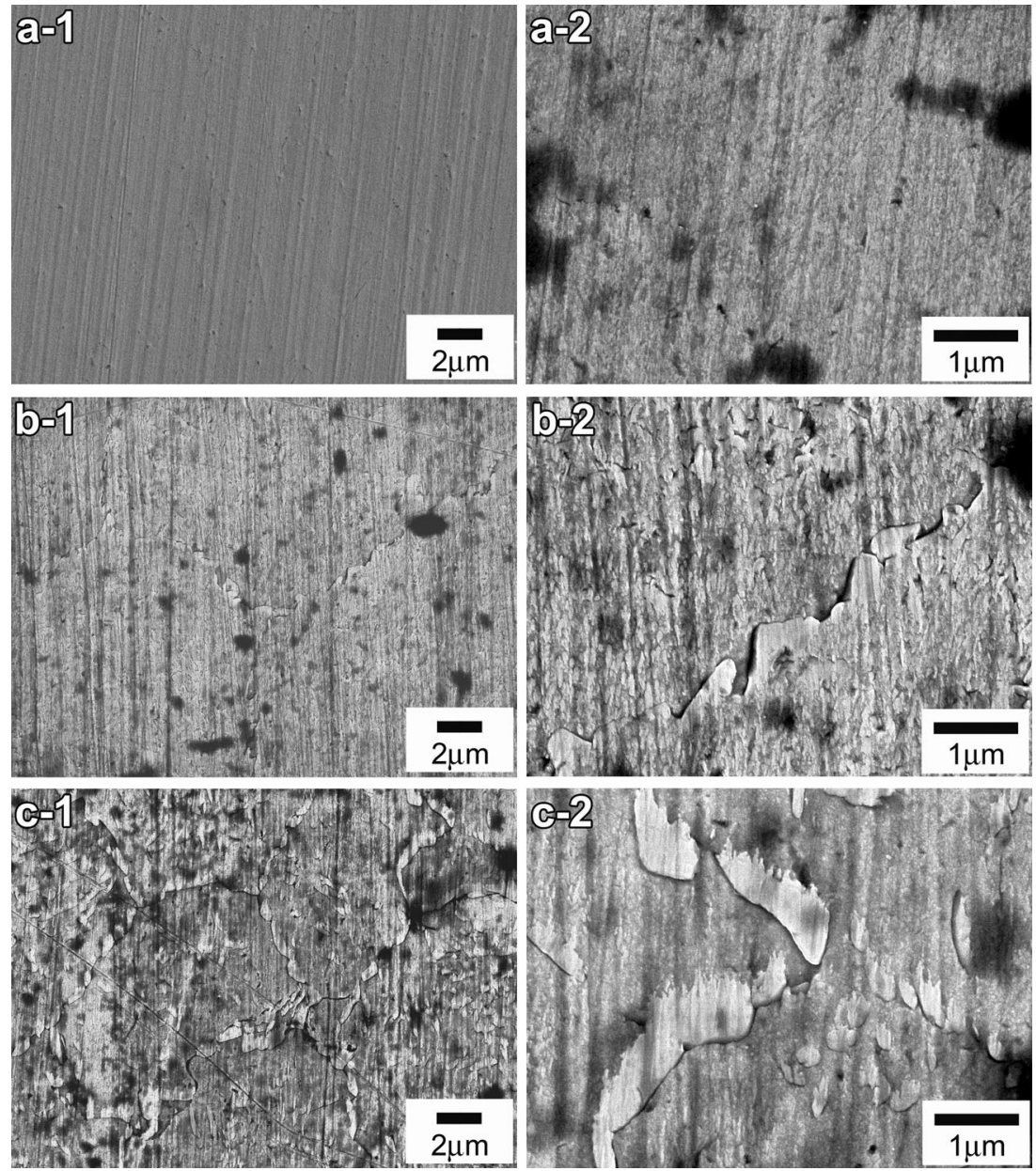

heat-treated specimen was $60 \mathrm{HV}$ higher than that of the solution-treated specimen. In the oxidation-treated specimen after the prefiring heat treatment (Fig. 4b), the grain interior and grain boundary precipitates became apparent. After simulated complete firing of the prefiring heat-treated specimen (Fig. 4c), the grain interior precipitates were apparently coarsened, and fine precipitates formed in the matrix. Therefore, the specimens in Figs. 2 to 4 showed the same microstructure after simulated complete firing. From the above, in the two types of softening heat-treated specimens after casting, the cooling process after oxidation induced grain interior precipitation, resulting in hardening, as in the as-cast specimen. In addition, the softening mechanism of the alloy during simulated complete firing was not changed by the softening heat treatment.

\section{Change in phase transformation of the as-cast and softening heat-treated alloys by simulated porcelain firing}

The change in the phase transformation by simulated porcelain firing in the as-cast specimen, and softening heat-treated specimens was examined by XRD. Figure 5 shows the change in the XRD patterns by oxidation (1) and complete firing (2) of the as-cast specimen (a) and solution-treated (b) or prefiring heat-treated (c) specimens after casting. In the as-cast specimen (Fig. 5a), a face-centered cubic (f.c.c.) phase with a lattice parameter of $a_{200}=3.988 \AA$ (the $\alpha$ phase) was the main phase consisting the matrix. In addition, there was a weak XRD peak of the second phase (the $\beta$ phase) in the lower diffraction angle side of the (200) $\alpha$ XRD peak. This corresponded to the XRD peak of the precipitates shown in the FE-SEM images of the as-cast specimen (Fig. 2). During the simulated porcelainfiring process $(a+1, a+2)$, the shape and position of the XRD peaks for the main $\alpha$ phase did not change. On the other hand, the intensity of the $\beta$ diffraction peak increased without any change in position, and a new XRD peak was observed in the higher diffraction angle side of the (200) $\alpha$ peak. From the $\mathrm{XRD}$ analysis, the XRD peak in the lower diffraction angle side of the (200) $\alpha$ peak was identified as the (200) peak of the $\beta$ phase with a lattice parameter of $a_{200}=4.096 \AA$. In addition, newly appeared diffraction peak in the higher diffraction angle side of the (200) $\alpha$ peak was identified as the (002) peak of the $\beta$ phase with a lattice parameter of $c_{002}=3.738 \AA$. The (111) $\beta$ peak overlapped with the (111) $\alpha$ peak, which is because the lattice parameter, $a$, of the $\alpha$ phase was smaller than $a$ but larger than $c$ of the $\beta$ phase. From the above, the precipitates 


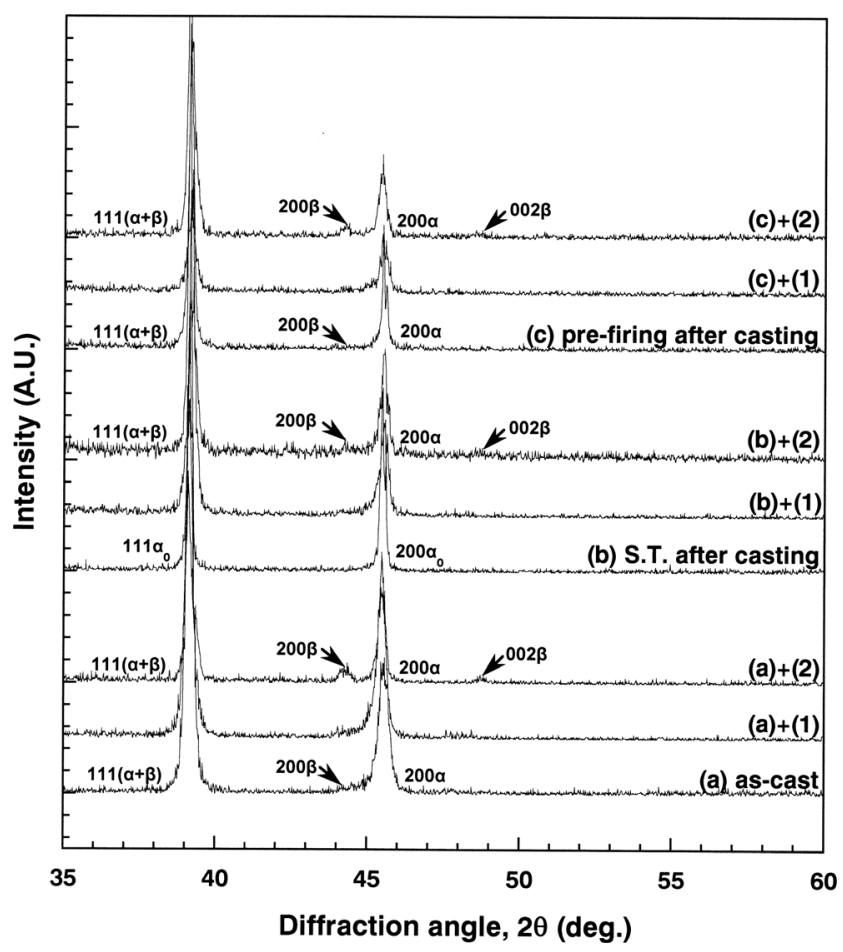

Fig. 5 Change in the XRD pattern of the as-cast specimen, and solutiontreated (S.T.) or prefiring heat-treated specimens after casting during simulated porcelain firing: as-cast (a), solution-treated after casting (b), prefiring heat-treated after casting (c), oxidation treated (1), complete firing simulated (2)

of various sizes and shapes, which appeared before and during simulated porcelain firing, were found to be composed of the same face centered tetragonal (f.c.t.) $\beta$ phase.

In the solution-treated (S.T.) specimen after casting (Fig. 5b), a single phase of an f.c.c. structure with a lattice parameter of $a_{200}=3.986 \AA$ (the $\alpha_{0}$ phase) was obtained. By simulated porcelain firing $(b+2)$ new XRD peaks formed in the same position with those of the $\beta$ precipitates. In the prefiring heat-treated specimen after casting (Fig. $5 \mathrm{c}$ ), the main phase was an f.c.c. structure with a lattice parameter of $a_{200}=3.988 \AA$ (the $\alpha$ phase). At this time, the peak intensity of the $\beta$ precipitates was quite weak. After simulated porcelain firing $(c+1, c+2)$, however, the peak intensity of the $\beta$ precipitates increased gradually, as observed in the as-cast specimen (a) and solution-treated specimen after casting (b).

In all the specimens tested, the increase in hardness by the oxidation treatment was related to the precipitation of the $\beta$ phase from the $\alpha$ matrix. By considering the gap of the lattice parameter between the f.c.t. $\beta$ precipitates and the f.c.c. $\alpha$ matrix, the increase in hardness can be attributed to formation of severe lattice strain in the interphase boundaries between the $\beta$ precipitates and the surrounding $\alpha$ matrix $[12,14,15]$. Through the remainder of the firing process, the hardness decreased gradually, even though the peak intensity of the $\beta$ precipitates increased further. FE-SEM, which showed the microstructural coarsening of the $\beta$ precipitates through subsequent firing
Table 5 EDS analysis after simulated completed firing of the as-cast specimen and solution-treated (S.T.) or prefiring heat-treated specimens after casting

\begin{tabular}{llllllll}
\hline Specimen & Region (at. \%) & Pd & Ag & Au & Sn & In & Ru \\
\hline As-cast & Matrix 1 & 56.8 & 27.0 & 9.3 & 3.3 & 3.5 & 0 \\
& Matrix 2 & 56.2 & 27.0 & 8.8 & 4.0 & 4.0 & 0 \\
& Precipitate 1 & 73.1 & 4.0 & 2.3 & 11.1 & 8.1 & 1.3 \\
& Precipitate 2 & 72.7 & 5.1 & 3.0 & 11.1 & 7.0 & 1.2 \\
& Precipitate 3 & 73.0 & 5.6 & 3.1 & 10.3 & 7.1 & 0.9 \\
S.T. & Matrix 1 & 56.0 & 28.7 & 9.4 & 3.1 & 2.8 & 0 \\
& Matrix 2 & 55.6 & 28.6 & 9.9 & 2.9 & 3.1 & 0 \\
& Precipitate 1 & 67.6 & 13.3 & 5.1 & 8.3 & 5.7 & 0 \\
Prefiring & Precipitate 2 & 66.4 & 13.6 & 4.9 & 8.9 & 6.1 & 0 \\
heat-treated & Matrix 1 & 57.3 & 27.0 & 9.3 & 3.3 & 3.1 & 0 \\
& Matrix 2 & 56.1 & 27.8 & 9.0 & 3.6 & 3.4 & 0 \\
& Precipitate 1 & 72.1 & 6.1 & 3.0 & 11.0 & 7.8 & 0 \\
& Precipitate 2 & 70.4 & 8.1 & 3.3 & 10.8 & 7.4 & 0 \\
\hline
\end{tabular}

process, indicated that softening resulted from the release of lattice strain by the reduced interphase boundaries between the coarsened $\beta$ precipitates and surrounding matrix $[3,5]$.

EDS was performed on the as-cast specimen, and solutiontreated or prefiring heat-treated specimens after casting to examine the elemental distribution in the matrix and precipitate after simulated complete firing. Table 5 lists the EDS results. In the matrix region of all the specimens tested, the elemental distribution was similar to the chemical composition of the asreceived alloy (Table 1). Therefore, the $\alpha$ matrix was composed of the $\mathrm{Pd}-\mathrm{Ag}-\mathrm{Au}$-rich phase of an f.c.c. structure. In the precipitates of all the specimens tested, Ag and Au decreased, whereas Pd, Sn, and In increased. XRD, which showed that the $\beta$ phase was the ordered f.c.t. phase with lattice parameters of $a_{200}=4.096 \AA$ and $c_{002}=3.738 \AA$, indicated that the grain interior and grain boundary precipitates appeared to be composed of the ordered $\mathrm{Pd}_{3}(\mathrm{Sn}, \mathrm{In})$ phase with an f.c.t. structure [14-16]. Overall, softening heat treatment for easy alloy processing before porcelain firing did not affect the hardness, microstructure, phase transformation, and elemental distribution of the alloy after simulated porcelain firing.

\section{Conclusions}

The change in hardness and its mechanism by simulated porcelain firing of an as-cast and softening heat-treated low-goldcontent alloy for bonding porcelain was elucidated by examining the change in hardness, microstructure, phase transformation, and elemental distribution during simulated porcelain firing.

(1) In the as-cast specimen, the hardness increased by oxidation, and as the specimen underwent a further 
porcelain-firing process, the hardness decreased gradually to be softer than the as-cast state.

(2) Hardening by oxidation of the as-cast specimen was induced by grain interior precipitation of the ordered $\mathrm{Pd}_{3}(\mathrm{Sn}, \mathrm{In})$ phase, which resulted in the formation of severe lattice strain in the matrix.

(3) The softening by the complete firing process in the ascast specimen resulted from coarsening of the ordered $\mathrm{Pd}_{3}(\mathrm{Sn}, \mathrm{In})$ precipitates, which resulted in release of lattice strain by the reduced inter-phase boundaries between the coarsened precipitates and surrounding matrix.

(4) In the softening heat-treated specimen, the decrease in hardness by the softening heat treatment was almost recovered at the oxidation-treated state, the first stage of porcelain-firing cycles. From the first opaque-treated state, there was little difference between the hardness of the as-cast specimen, and the softening heat-treated specimens after casting.

(5) The mechanism of hardening by oxidation and subsequent softening by the complete firing process was unaffected by the softening heat treatment before porcelain firing in a low-gold-content alloy for bonding porcelain.

Acknowledgments This research was supported by Basic Science Research Program through the National Research Foundation of Korea (NRF) funded by the Ministry of Education, Science and Technology (grant number: NRF-2014R1A1A2055018)

Open Access This article is distributed under the terms of the Creative Commons Attribution License which permits any use, distribution, and reproduction in any medium, provided the original author(s) and the source are credited.

\section{References}

1. German RM (1980) Hardening reaction in a high-gold content ceramo-metal alloy. J Dent Res 59:1960-1965
2. Fischer J, Fleetwood PW (2000) Improving the processing of highgold metal-ceramic frameworks by a pre-firing heat treatment. Dent Mater 16:109-113

3. Vermilyea SG, Cai Z, Brantley WA, Mitchell JC (1996) Metallurgical structure and microhardness of four new palladiumbased alloys. J Prosthodont 5:288-294

4. Li D, Baba N, Brantley WA, Alapati SB, Heshmati RH, Daehn GS (2010) Study of Pd-Ag dental alloys: examination of effect of casting porosity on fatigue behavior and microstructural analysis. $\mathrm{J}$ Mater Sci Mater Med 21:2723-2731

5. Jeon BW, Kim SM, Kim HI, Kwon YH, Seol HJ (2014) Hardening effect of pre- and post-firing heat treatment for a firing-simulated Au-Pd-In metal-ceramic alloy. Gold Bull 47:255-261. doi:10. 1007/s13404-014-0149-6

6. Yamamoto M (1982) The metal ceramics. Quintessence, Tokyo

7. Wang JN, Liu WB (2006) A Pd-free high gold dental alloy for porcelain bonding. Gold Bull 39:114-120

8. Liu WB, Wang JN (2007) Strengthening of a Pd-free high gold dental alloy for porcelain bonding by a pre-firing heat treatment. Dent Mater 23:1136-1141

9. Hisatsune K, Otha M, Yamane M (1982) Effect of cooling rate on ordering behavior in a CuPt alloy. Dent Mater J 1:1-7

10. Udoh K, Hisatsune K, Yasuda K, Otha M (1984) Isothermal agehardening behavior in commercial dental gold alloys containing palladium. Dent Mater J 3:253-261

11. Seol HJ, Lee DH, Lee HK, Tanaka Y, Okuno O, Kwon YH, Kim HI (2006) Age-hardening and related phase transformation in an experimental $\mathrm{Ag}-\mathrm{Cu}-\mathrm{Pd}-\mathrm{Au}$ alloy. J Alloys Compd 407:182-187

12. Pan LG, Wang JN (2007) Age-hardening behavior of a low-gold dental alloy. J Mater Sci Mater Med 18:171-177

13. Guo WH, Brantley WA, Clark WAT, Monaghan P, Heshmati RH (2007) Annealing study of palladium-silver dental alloys: Vickers hardness measurements and SEM microstructural observations. J Mater Sci Mater Med 18:111-118

14. Hisatsune K, Hasaka M, Sosrosoedrdjo BI, Udoh K (1990) Agehardening behavior in a palladium-base dental porcelain fused alloy. Mater Charact 25:177-184

15. Guo WH, Brantley WA, Clark WAT, Monaghan P, Mills MJ (2003) Transmission electron microscopic investigation of a Pd-Ag-In-Sn dental alloy. Biomaterials 24:1705-1712

16. Hisatsune K, Udoh K, Nakagawa M, Yasuda K (1987) Three distinguishable phase changes during slow-cooling in commercial dental alloys for porcelain bonding. Dent Mater J 6: $54-63$ 